\title{
Mastery and Performance Goals Predict Epistemic and Relational Conflict Regulation
}

\author{
Céline Darnon \\ Université Pierre Mendès France \\ Sheree M. Schrager \\ University of Wisconsin-Madison
}

\author{
Dominique Muller \\ Université Paris Descartes
}

\author{
Nelly Pannuzzo \\ Université Pierre Mendès France
}

\author{
Fabrizio Butera \\ Université de Lausanne
}

\begin{abstract}
The present research examines whether mastery and performance goals predict different ways of reacting to a sociocognitive conflict with another person over materials to be learned, an issue not yet addressed by the achievement goal literature. Results from 2 studies showed that mastery goals predicted epistemic conflict regulation (a conflict regulation strategy focused on the attempt to integrate both points of view), whereas performance goals predicted relational conflict regulation (a conflict regulation strategy focused on the evaluation and affirmation of self-competence). Study 1 shows these links via direct self-report measures of conflict regulation. Study 2 shows the same links using the amount of competence reported for the self and for the other as subtle measures of conflict regulation.
\end{abstract}

Keywords: conflict regulation, performance goals, mastery goals

Today, Audrey and Mandy, two students of the psychology department, are working together on an exercise they have to carry out for one of their classes. As they try to solve the first problem, Audrey suggests an answer, Answer A. But Mandy disagrees; she thinks the solution is B and explains why. The reader has probably also encountered such situations, as disagreement is a common occurrence when one is working with another person on academic materials. As soon as two people work with each other, indeed, this type of disagreement is likely to occur.

Céline Darnon and Nelly Pannuzzo, Laboratoire de Psychologie Sociale de Grenoble-Chambéry, Université Pierre Mendès France, Grenoble, France; Dominique Muller, Laboratoire de Psychologie Sociale, Université Paris Descartes, Paris, France; Sheree M. Schrager, Department of Psychology, University of Wisconsin-Madison, USA; Fabrizio Butera, Institut des Sciences Sociales et Pédagogiques, Université de Lausanne, Lausanne, Switzerland.

Céline Darnon is now at the Laboratoire de Psychologie Sociale et Cognitive, Université Blaise Pascal, Clermont Ferrand, France. Dominique Muller is now at the Laboratoire de Psychologie Sociale de GrenobleChambéry, Université Pierre Mendès France, France.

Part of this work was conducted during Céline Darnon's doctoral dissertation under the supervision of Fabrizio Butera and was written during her postdoctorate at the University of Wisconsin-Madison, thanks to a Fulbright fellowship. This research was supported by an Ecole et Sciences Cognitives fund granted by the French Ministry for Research and by the Swiss National Science Foundation.

Correspondence concerning this article should be addressed to Fabrizio Butera, Institut des Sciences Sociales et Pédagogiques, Université de Lausanne-Anthropole. CH 1015, Lausanne, Switzerland. E-mail: fabrizio.butera@unil.ch
Researchers have called this situation a sociocognitive conflict (Buchs, Butera, Mugny, \& Darnon, 2004; Doise \& Mugny, 1984) because disagreeing on a task to perform entails both a cognitive and a social component. On the one hand, this conflict is cognitive because it introduces doubt about the content or the solution of the task, an imbalance in knowledge as described by Piaget's (1985) notion of cognitive conflict (see also Limon, 2001). On the other hand, this conflict is also social, as it represents a confrontation between two (or more) people; in this respect, disagreeing introduces doubt about relative competence (i.e., "Who is more competent?" cf. Butera \& Mugny, 2001; Quiamzade \& Mugny, 2001). It is important to note that in this literature, the term conflict differs from how it is used in the conflict resolution literature (Deutsch, 1973) because (a) it is not always a conflict of interests (in fact, the word is mainly used to refer to conflict of knowledge) and (b) it does not necessarily imply that the two parties in conflict must reach an agreement (as sociocognitive conflict can be regulated by a change in knowledge at the individual level).

Academic tasks are usually characterized by the fact that there is an answer that is better than the others. Being in sociocognitive conflict with someone means that the other person might be right and that, as a consequence, he or she might be more competent than oneself. Thus, even if sociocognitive conflict can make individuals doubt the validity of their own knowledge, which can represent an interesting potential for engagement in the task, epistemic curiosity, and cognitive reconstruction (Berlyne, 1960; Ohlsson, 1996; Piaget, 1985), it also has the potential to threaten self-competence (Butera \& Mugny, 2001; Butera, Mugny, \& Tomei, 2000). 
How can individuals cope with this sociocognitive conflict? Let us go back to our opening example. From Audrey's point of view, what does the disagreement with Mandy mean? First, as mentioned earlier, the sociocognitive conflict introduces a doubt about the validity or accuracy of each proposition. To address this sociocognitive conflict, then, Audrey can try to work through the problem again and examine the validity of each proposition. This has been called epistemic conflict regulation (Doise \& Mugny, 1984; Mugny, De Paolis, \& Carugati, 1984). However, from Audrey's point of view, the sociocognitive conflict could also mean that she is less competent than her friend. On a task in which competence is so highly valued (Mugny, Butera, Quiamzade, Dragulescu, \& Tomei, 2003; Nicholls, 1984), feeling incompetent can affect her perception of self-worth (Covington, 1984, 1992; Steele, 1988; Tesser, 1988). In this case, she may just react by defending and protecting her own competence-for example, by demonstrating that she is right and that Mandy is wrong. This is what Doise and Mugny (1984) referred to as relational conflict regulation. Again, it should be noted that conflict regulation is not conflict resolution (Deutsch, 1973), as regulating sociocognitive conflict in one way or another does not necessarily imply that this conflict is terminated.

Mugny et al. (1984, 2003; Butera \& Mugny, 2001; Quiamzade \& Mugny, 2001) have produced an abundant line of research showing that modes of conflict regulation correspond to different perceptions of the task and the other person. This research indicates that if individuals are led to believe in the complementarity of their points of view (Butera, Gardair, Maggi, \& Mugny, 1998; Butera \& Mugny, 2001; Butera et al., 2000; Johnson, Johnson, \& Smith, 2000), then epistemic regulation is favored. Conversely, if the other person is presented as a competitor (e.g., Butera \& Mugny, 1995; Butera et al., 1998, 2000; Johnson \& Johnson, 1985) or a person susceptible to evaluating competence (Butera et al., 2000; Quiamzade, Tomei, \& Butera, 2000; Tjosvold, Johnson, \& Fabrey, 1980), then it is likely that sociocognitive conflict will be regulated in a relational way.

For these researchers (e.g., Butera \& Mugny, 2001; Mugny et al., 2003), the impossibility for individuals to recognize the other's competence is one of the main processes responsible for the fact that in a competitive situation, the sociocognitive conflict is regulated in a relational way: If the situation is competitive, the other's competence threatens self-competence. This is not the case in a noncompetitive situation, in which another's competence is unrelated to one's own and thus can be accepted (Butera \& Mugny, 1995). Additionally, the more competitive the situation is, the larger the difference is between reported self-competence (higher) and the other's competence (lower; Butera \& Mugny, 1995; Butera et al., 2000, Study 3).

This idea is consistent with the point of view that individuals usually evaluate others in a very positive way (Sears, 1983) but that this bias also sometimes can be reduced. Drozda-Senkowska and Personnaz (1988) showed, for example, that as soon as participants anticipated being in competition with the person they were evaluating, this evaluation was less positive. In the same vein, some authors have demonstrated that threat (in their studies, failure) could decrease the evaluation that some participants made of a target (Beauregard \& Dunning, 1998) and enhance selfserving bias (Dunning, Leuenberger, \& Sherman, 1995).
Taken together, these results show that sociocognitive conflict regulation corresponds to different representations of self- and other's competence. When they regulate the sociocognitive conflict in a relational way, individuals try to demonstrate that they are right and that the other person is wrong. Conversely, when they regulate the sociocognitive conflict in an epistemic way, they recognize the other person's competence and try to understand how his or her point of view can complement their own understanding. This research also underlines that the two modes of conflict regulation reflect different focus. Epistemic regulation corresponds to a focus on the task, whereas relational regulation corresponds to a focus on competence evaluation and social comparison.

Similarly, in the domain of achievement goals, a large amount of research has studied how the goals students pursue when they perform an achievement task can lead them to focus their attention on different elements of the situation (Butler, 1992; Cury, Sarrazin, $\&$ Famose, 1997). In particular, the achievement goals literature has argued that two types of goals exist (for reviews, see Dweck, 1986; Harackiewicz, Barron, \& Elliot, 1998; Maehr, 1984; Nicholls, 1984; Pintrich \& Schunk, 2002; Urdan, 1997): Mastery goals_also labeled learning goals (Dweck, 1986, 1992) or taskfocused goals (Nicholls, 1984)_correspond to the will to acquire knowledge and develop competences. Performance goals-also referred to as ego-focused goals (Nicholls, 1984) or relative-ability goals (Urdan, 1997) — correspond to the will to demonstrate competences relative to others. Recent research suggests that each of these two types of goals can be divided further into approach and avoidance goals (Elliot \& Harackiewicz, 1996; Elliot \& McGregor, 2001). In this article, however, we focus on the approach form of performance and mastery goals, the two goals that have been the most examined in the literature and, paradoxically, the two goals whose effects are still the object of much debate (cf. Harackiewicz, Barron, Pintrich, Elliot, \& Thrash, 2002; Midgley, Kaplan, \& Middleton, 2001).

The achievement goals literature has shown that goals strongly affect the way individuals confront an achievement task. Research shows, for example, that mastery goals favor a deep processing of the task, whereas performance goals favor a surface processing (Darnon \& Butera, 2005; Elliot, McGregor, \& Gable, 1999; Nolen, 1988). Moreover, it has been shown that mastery-oriented students explain failure in terms of lack of effort and, as a consequence, react to failure by making more of an effort (Ames \& Archer, 1988; Ames, Russel, \& Felker, 1977). On the contrary, performance-oriented students tend to attribute failure to a lack of abilities and, as a consequence, can be vulnerable to helplessness (Diener \& Dweck, 1980; Dweck \& Leggett, 1988). This is why Dweck (1986) qualified the pattern of answers resulting from the endorsement of mastery goals as adaptive and the pattern resulting from the endorsement of performance goals as maladaptive (see also Dweck, 1992).

More interesting in the context of this article, this research indicates that different goals lead to different kinds of focus. Mastery goals favor a task focus, whereas performance goals favor a focus on social comparison. Many studies have found a positive link between mastery goals and intrinsic interest in the task (for reviews, see Barron \& Harackiewicz, 2000; Heyman \& Dweck, 1992; Rawsthorne \& Elliot, 1999). This effect has been observed both on self-report measures (e.g., Harackiewicz, Barron, Carter, 
Lehto, \& Elliot, 1997; Harackiewicz, Barron, Tauer, Carter, \& Elliot, 2000; Harackiewicz, Barron, Tauer, \& Elliot, 2002) and on behavioral measures, such as the time spent on the task during a free time period (e.g., Barron \& Harackiewicz, 2001; Koestner, Zuckerman, \& Koestner, 1987; R. M. Ryan, 1982). Although interest in evaluative information (rather than interest in the task itself) has been examined less in this field, some results do indicate that it can also vary according to goals. Some research has shown, for example, that in a mastery goals context, students were not sensitive to evaluative social comparison information (Jagacinski \& Nicholls, 1987; Sansone, 1986). On the contrary, this information was important and influenced affect in a performance goals context. In a more direct fashion, Butler (1992) examined the time participants spent on different kinds of information: information about the task (the solution suggested by another participant) or information about the way to calculate one's own ability score. Her results indicated that participants in the mastery goal condition spent more time on the information about the task than participants in the performance goal condition. Moreover, the latter spent more time on the evaluative information than the former. In two other experiments, Butler (1993) showed that participants in an egoinvolving condition requested more normative information (their range compared with other students), whereas participants in the task-involving condition requested more information about the task (the best possible solutions; see Cury et al., 1997, for similar results on a motor task).

The perception of other persons has not been a major concern in the achievement goals framework. As Levy, Kaplan, and Patrick (2004) recently noted, "The vast majority of this research ... has addressed how individuals' achievement goals are associated with beliefs or behaviors about themselves and academic tasks, but there has been little attention to attitudes and behaviors toward others" (p. 1; see also Kaplan, 2004, for a similar discussion). Even though this question has not been addressed directly, however, some elements can be found in this literature suggesting that other people can be perceived either as informational supports or as threats, depending on the goals pursued. For example, mastery goals have been shown to favor the search for information from others (Cheung, Ma, \& Shek, 1998), the willingness to cooperate with them (Kaplan, 2004; Levy et al., 2004), and the willingness to ask for help (Butler \& Neuman, 1995; Karabenick, 2003; Middleton \& Midgley, 1997; A. M. Ryan \& Pintrich, 1997; A. M. Ryan, Pintrich, \& Midgley, 2001). On the contrary, performance goals appear to lead participants to perceive the other as a threat (A. M. Ryan \& Pintrich, 1997) and are linked to the avoidance of help seeking (Karabenick, 2003; A. M. Ryan \& Pintrich, 1997). Recently, Kaplan's (2004, Study 1) research showed that performance goals could lead to a less positive evaluation of out-group members than mastery goals. Thus, mastery goals seem to lead students to recognize the other as competent, which does not seem to be the case for performance goals.

\section{Overview and Hypotheses}

If, as shown in the literature, goals affect the way the task is solved (e.g., Nolen, 1988), the way an individual perceives and reacts to failure (e.g., Ames et al., 1977), and the way an individual perceives the other persons (e.g., A. M. Ryan \& Pintrich, 1997), then it is likely that they also affect the way sociocognitive conflict is regulated. As we have presented, mastery goals have been shown to be linked to a deep treatment of the material to be learned, to a focus on the problem, to the perception of the other as a help, and to willingness to cooperate. Epistemic regulation means examining the content and the validity of each of the propositions in conflict and making more effort toward a better understanding (e.g., by working through the problem again; e.g., Mugny et al., 1984). It also corresponds to the recognition of the other's competence and of the fact that the other's point of view can be helpful in understanding the problem (Butera \& Mugny, 2001). In a sociocognitive conflict situation, mastery goals should then predict epistemic conflict regulation.

On the contrary, performance goals make students concerned with being competent and focused on social comparison with others (Nicholls, 1984). Moreover, such goals favor the representation of other people as threats (A. M. Ryan \& Pintrich, 1997). One of the characteristics of relational regulation is that attention is focused on social comparison and competence issues (Butera \& Mugny, 2001). Thus, performance goals should lead participants to react to a sociocognitive conflict by trying to show that they are right and the other is wrong - that is, to regulate the sociocognitive conflict in a relational manner.

Returning to our example, we believe that if the main goals Audrey is pursuing when the sociocognitive conflict occurs are mastery goals, she may perceive the sociocognitive conflict as an indication that she needs to work through the problem again to understand it better. Thus, mastery goals should lead her to regulate the sociocognitive conflict in an epistemic way. However, if her main goals are performance goals, then she is more likely to perceive the sociocognitive conflict as a threat to her competence and regulate it in a relational way.

The two presented studies test the hypothesis that mastery and performance goals predict distinct reactions to sociocognitive conflict. We examined these hypotheses in Study 1 by asking participants to report, after imagining they had interacted with a disagreeing other, how they would have regulated the sociocognitive conflict. In Study 2, we examined the same hypotheses through more subtle measures of conflict regulation: the competence attributed to oneself and to the disagreeing other.

\section{Study 1}

In Study 1, participants were asked to imagine a discussion with another person who disagreed with them about an experiment they had studied in class the previous semester. They were then asked to report the extent to which, in this situation, they would have regulated the sociocognitive conflict in a relational or an epistemic way.

\section{Method}

\section{Participants}

Fifty-one French introductory psychology students with a mean age of 19.31 years $(S D=3.61)$ were invited to participate in this study during one of their introductory psychology classes. This sample was composed of 41 women and 8 men ( 2 did not report their gender).

\section{Procedure}

Participants were asked to fill out a questionnaire. In the first part of the questionnaire, students were asked to report the main results and implica- 
tions of an experiment they had studied in one of their classes the semester before, namely Milgram's (1974) first experiment on compliance with authority. This experiment was chosen because students usually have a good recollection of it. We expected them to report the following idea: In a situation in which an authority asks an individual to do something, the individual usually does it even if he or she thinks it is unfair or wrong. All participants in the sample did report some version of this idea. After recalling the results of this experiment, participants filled out a questionnaire assessing their achievement goals.

The second part of the questionnaire was presented as a debate. Participants read the following instructions:

Let's imagine now that you talk about this experiment with another introductory psychology student. Here is an extract of his (her) point of view: "I think that in this experiment, the researchers didn't take people's personality enough into account. Indeed, some people lack critical thinking and comply easily with authority, but these people are rare. Most normal people are able to judge the legitimacy of a decision. They will comply when the authority is justified, or when (s)he is more expert than they are, but won't if they think that what the authority asked them is unfair or illegitimate."

Participants were then asked to imagine a discussion with this person and to write down what they would like to tell him or her. Then they were asked to report to what extent, during this debate, they would try to regulate the conflict in an epistemic way or a relational way. Once the questionnaire was completed, the experimenter told participants that they could learn more about this experiment by requesting information from their professor at the end of their class and then left.

\section{Measures}

Achievement goals. Mastery and performance goal items were extracted from Elliot and McGregor's (2001) scale, validated in French by Darnon and Butera (2005). There were three performance-approach goal items (e.g., "It is important for me to do better than other students") and three mastery-approach goal items (e.g., "I want to learn as much as possible from this class"). Students responded on a scale ranging from 1 (not at all) to 7 (completely). Descriptive statistics are presented in Table 1.

Epistemic and relational conflict regulation. Participants were first asked to report the amount of perceived disagreement with the other student. Then they were asked to report to what extent (on a scale ranging from $1=$ not at all to $7=$ completely) they would regulate sociocognitive conflict in an epistemic and in a relational way (e.g., "Try to examine the conditions under which each point of view could help you understand" for epistemic regulation; "Try to resist by maintaining your initial position" for relational regulation). All of these items (conflict regulation and perceived disagreement) were created on the basis of the definition provided by the sociocognitive conflict literature. The three items of epistemic regulation and the three items of relational regulation are presented in Table 2. Descriptive statistics are presented in Table 1.

\section{Results}

\section{Factorial Structure of the Scales}

In preliminary analyses, factor analyses were conducted on the six goals items via principal-components extraction with promax rotation. ${ }^{1}$ These analyses revealed the expected two-factor structure of the scale: Factor 1 accounted for $62.9 \%$ of the variance and comprised the three mastery goals items. Factor 2 accounted for $21 \%$ of the variance and consisted of the three performance goals items. All items loaded above .70 on their primary factor.
Table 1

Study 1: Goal Endorsement and Conflict Regulation

\begin{tabular}{lccccc}
\hline \multicolumn{1}{c}{ Variable } & & & Observed & Possible & \\
range & range & $\alpha$ \\
\hline Mastery goals & 4.03 & 1.64 & $1.00-7.00$ & $1-7$ & .94 \\
Performance goals & 2.65 & 1.18 & $1.00-5.33$ & $1-7$ & .85 \\
Epistemic conflict regulation & 3.90 & 1.13 & $1.00-7.00$ & $1-7$ & .82 \\
Relational conflict regulation & 3.93 & 1.65 & $1.33-6.33$ & $1-7$ & .91 \\
\hline
\end{tabular}

The same factor analyses were conducted on the six conflict regulation items. The results of these analyses are presented in Table 2. They yielded two factors. Factor 1 comprised the three items of relational regulation and accounted for $52.7 \%$ of the variance. Factor 2 comprised the three items of epistemic conflict regulation and accounted for $26.3 \%$ of the variance. As can be seen in Table 2, all items loaded above .70 on their primary factor. Scale reliabilities are presented in Table 1.

\section{Achievement Goals as Predictors of Conflict Regulation}

Zero-order correlations are reported in Table 3. To test our hypotheses, we conducted regression analyses with three predictors: performance goals, mastery goals, and the interaction between these two variables, calculated on the basis of the two centered variables. Interaction terms were included in the analyses because recent research (e.g., Barron \& Harackiewicz, 2001) suggests that, instead of being independent of one another, mastery and performance goals can interact on different outcomes. In preliminary analyses, gender (coded -1 for men, 1 for women) and age were included in the analyses. Neither gender $(B=0.14$; $t<1)$ nor age $(B=-0.06), t(42)=-1.09, p=.28$, predicted relational regulation. Age did not predict epistemic conflict regulation $(B=-0.02 ; t<1)$. The only significant effect was a gender effect on epistemic conflict regulation $(B=0.69), t(42)=3.91$, $p<.001$, such that this mode of regulation was stronger for women than for men. Complete analyses of covariance (Yzerbyt, Muller, \& Judd, 2004) were then conducted with gender and age. Because the inclusion of these variables did not change the effects and because the only significant effect (i.e., gender effect on epistemic conflict regulation) was not theoretically relevant in the present experiment, these variables were removed from the final model.

Epistemic regulation. As expected, mastery goals significantly and positively predicted the reported amount of epistemic conflict regulation $(B=0.41), t(46)=4.07, p<.001\left(\eta^{2}=.27\right)$. This was not the case for performance goals $(B=-0.15), t(46)=-1.04$, $p=.30\left(\eta^{2}=.02\right)$, or for the interaction $(B=0.04 ; t<1)$.

Relational regulation. Also as expected, performance goals significantly and positively predicted the reported amount of relational conflict regulation $(B=0.57), t(46)=2.75, p<.009\left(\eta^{2}=\right.$

\footnotetext{
${ }^{1}$ It is worth noting that in Studies 1 and 2 the sample size was fairly small. Some authors, however, have argued that factor analysis can be conducted on small samples (between 50 and 100 participants, as in our samples; Sapnas \& Zeller, 2002). This is even safer when the communality is high (MacCallum, Widaman, Zhang, \& Hong, 1999), which is the case for the items used in both present studies.
} 
Table 2

Conflict Regulation Items and Their Factor Loading (Study 1) Via Principal-Components Extraction With Oblique Rotations (Promax)

\begin{tabular}{lrr}
\hline \multicolumn{1}{c}{ Item } & Factor 1 & Factor 2 \\
\hline When disagreements occurred, to what extent did you . . & .930 & .313 \\
$\quad$ try to show you were right? & .920 & .301 \\
try to resist by maintaining your initial position? & .901 & .278 \\
try to show your partner was wrong? & .222 \\
$\quad$ try to think about the text again in order to understand better? & .922 \\
try to examine the conditions under which each point of view could help you & .287 & .876 \\
$\quad$ understand? & .340 & .764 \\
try to think of a solution that could integrate both points of view? &
\end{tabular}

.14). Neither mastery goals $(B=0.24), t(46)=1.63, p=.11$ $\left(\eta^{2}=.05\right)$, nor the interaction $(B=0.04 ; t<1)$ significantly predicted this mode of regulation. A summary of regression parameters is presented in Table 4.

\section{Discussion}

As expected, the results of this first study show that endorsed goals did predict different modes of conflict regulation. In particular, mastery goals - but not performance goals-predicted epistemic conflict regulation. On the contrary, performance goalsbut not mastery goals-predicted relational conflict regulation.

It is worth noting that in this study, we measured the mode of conflict regulation by asking participants to report the extent to which they would regulate the sociocognitive conflict in the epistemic and relational modes. However, one could argue that conflict regulation is a less conscious process and that it is perhaps too sensitive to social desirability effects to be assessed via direct self-report. The focus of the second study is to provide evidence of the link between mastery and performance goals, on the one hand, and conflict regulation strategies, on the other, using a more subtle measure of conflict regulation. As mentioned earlier, regulating sociocognitive conflict in an epistemic manner means taking into account the other's point of view, recognizing its validity, and, as a consequence, recognizing the other's competence. On the contrary, regulating sociocognitive conflict in a relational manner implies defending and asserting one's own competence. Therefore, in Study 2, conflict regulation was assessed by the competence attributed to oneself and to the person who disagreed.

Moreover, in Study 1, participants were merely led to imagine that they interacted with another person who disagreed. It is possible to think that this situation, because it implies a fictitious interaction, does not reflect how people react when they have to face a real sociocognitive conflict. In Study 2, participants were placed in a real, standardized sociocognitive conflict situation.

Finally, as developed earlier, research has shown that mastery goals favor the search for instructive information, whereas performance goals favor the search for normative evaluative information (Butler, 1992, 1993; Cury et al., 1997). However, none of this research has examined these links in a situation in which students interact with each other. As noted earlier, the classroom situation implies interaction with others, which makes the occurrence of sociocognitive conflicts particularly likely. Considering that the sociocognitive conflict is a situation very likely to occur in a classroom, it appears important to replicate these findings in a true sociocognitive conflict situation. That is the third aim of Study 2.

Study 2

In the present study, high school students were led to experience a real-rather than imagined-sociocognitive conflict situation. After this interaction, they were asked to report how competent they thought they and their partner were. Two weeks later, they had the opportunity to choose between different kinds of information they would like to receive-namely, the text or their grade. We expected that mastery goals would predict perceived partner's competence and that performance goals would predict perceived self-competence. We also expected goals to affect interest in different kinds of information, such that mastery goals would predict interest in the task, whereas performance goals would predict interest in the grade.

\section{Method}

\section{Participants}

Sixty-three teenagers with a mean age of 15.68 years $(S D=0.64)$ were invited to participate in this study during one of their classes. They were 10th grade students, 16 boys and 47 girls, from a high school in the suburb of Valence, France.

\section{Procedure}

The study was conducted in three different stages. First, during one of their classes, participants were asked to fill out a questionnaire assessing achievement goals. One week later, in the same class, the students were invited to participate in a "computer-mediated cooperative learning study," a task inducing a sociocognitive conflict (see the Materials section). When

Table 3

Study 1: Zero-Order Correlations Among Variables

\begin{tabular}{lcccr}
\hline \multicolumn{1}{c}{ Variable } & 1 & 2 & 3 & 4 \\
\hline 1. Mastery goals & - & & \\
2. Performance goals & $.50 * * *$ & - & & \\
3. Epistemic conflict regulation & $.51 * * *$ & .16 & - & \\
4. Relational conflict regulation & $.43 * *$ & $.51 * * *$ & $.32 *$ & - \\
\hline$* p<.05 . \quad * * p<.01 . \quad * * * p<.001$. & & &
\end{tabular}


Table 4

Unstandardized Regression Parameters (Bs) and Significance for Study 1 and Study 2

\begin{tabular}{lccccccc}
\hline & \multicolumn{2}{c}{ Study 1} & & \multicolumn{2}{c}{ Study 2} \\
\cline { 2 - 3 } \multicolumn{1}{c}{ Variable } & $\begin{array}{l}\text { Epistemic } \\
\text { regulation }\end{array}$ & $\begin{array}{c}\text { Relational } \\
\text { regulation }\end{array}$ & & $\begin{array}{c}\text { Perceived } \\
\text { other's compet. }\end{array}$ & $\begin{array}{c}\text { Perceived } \\
\text { self-compet. }\end{array}$ & $\begin{array}{c}\text { Asking for } \\
\text { the text }\end{array}$ & $\begin{array}{c}\text { Asking for } \\
\text { the grade }\end{array}$ \\
\hline Mastery goals & $0.41^{* * *}$ & 0.24 & & $0.38^{*}$ & & 0.01 & $0.55^{*}$ \\
Performance goals & -0.15 & $0.57^{* *}$ & & -0.05 & -0.21 \\
Mastery $\times$ Performance goals & 0.04 & 0.04 & & 0.17 & -0.03 & 0.02 & 0.11 \\
\hline
\end{tabular}

Note. compet. $=$ competence.

$* p<.05$. ** $p<.01$. *** $p<.001$.

this task was over, they filled out a questionnaire containing measures of perceived self- and other's competence. They also filled out a multiple choice questionnaire assessing how well they had learned the text. This was, in reality, a bogus questionnaire aimed at informing participants that they would get a grade reflecting how well they understood the text. They were then thanked and invited to go back to their classes. Two weeks later, the experimenter returned to one of the students' classes to collect the different interest measures. She then debriefed them and gave them the information they had requested.

\section{Materials}

The so-called computer-mediated cooperative learning study, the part of the experiment in which the sociocognitive conflict was introduced, was carried out in groups (between 10 and 16 participants) in a computerequipped room, with each participant sitting in front of a computer. Participants were told that they would interact in pairs, via computers, to discuss a text about eyewitness testimony. They were told that dyads were determined randomly.

To maximize the chance that the computer-mediated communication would be perceived as relevant, we first presented participants with an initial task demonstrating how important the other's point of view was (see Butera, Huguet, Mugny, \& Pérez, 1994, for more details on this task). Participants then began the target task on the computer. When they hit the start key, the first part of the text to learn appeared on their screen. After reading this first part of the text, they had to press a key allowing them to go to the next screen, on which a question about this first part was written. They were asked to type their answer and send it to their partner by hitting a send key. Contrary to what they were told, participants were not connected to each other, and nobody received this answer. Instead, the program was set up to send automatically, after a few seconds' delay, a prerecorded answer presented as the partner's answer. This answer had been prerecorded to induce a sociocognitive conflict. Questions were easy enough for all participants to give the correct answer, and the partner's answer (actually the prerecorded answer) was in disagreement with the participant's. For example, participants correctly answered the question "What are the effects of the presence of a weapon on the recall of a criminal event?" by reporting that it deteriorates the recall. The partner's answer was, "I rather thought that weapon presence enhances attentional focus, and then the witness is more attentive and better remembers the elements of the situation." This response was incorrect but seemed plausible with regard to common sense. Moreover, to the question "Which one of the two types of information processing (deep vs. surface) favors a global representation of the person?" all participants correctly answered, "deep processing." The partner's answer was, "I rather thought that the surface processing was the one which led to a global representation (taking into account only the main characteristics) whereas the deep processing took into account more information and thus favored a detailed vision, a specific one." Again, this response was incorrect but seemed plausible with regard to common sense. Disagreements were therefore based on incorrect an- swers from the partner but corresponded to a plausible (nonaberrant) point of view (as in Mugny, Lévy, \& Doise, 1978).

After reading this answer, participants were led to the following part of the text, and so on. The same procedure was repeated for the four parts of the text. To strengthen the credibility of the situation, for one of the questions, the partner's answer was in agreement with the participant's. For the three others, it was in disagreement.

\section{Measures}

Achievement goals. As in Study 1, mastery and performance goal items were extracted from Elliot and McGregor's (2001) scale, validated in French by Darnon and Butera (2005). The same three performance-approach goal items and three mastery-approach goal items were used. Descriptive statistics are presented in Table 5.

Reported self- and partner's competence. Perceived self-competence was assessed with three items. Participants were asked to report, after the task on the computer, how much they thought they "understood the text well," "managed to answer the questions well," and "are competent on this type of task" on a scale ranging from 1 (not at all) to 7 (very much).

The same items were used for assessing the partner's competence. Participants were asked to indicate how much they thought their partner "understood the text well," "managed to answer the questions well," and "is competent on this type of task" on a scale ranging from 1 (not at all) to 7 (very much). Descriptive statistics are presented in Table 5.

Interest in different kinds of information. When the experimenter went back to classes for the third part of the experiment, she explained to participants that they were allowed to receive some information about the experiment in which they had taken part 2 weeks before. That is, they could ask for a more detailed version of the text about eyewitness testimony (the text learned during this experiment) and the grade they had obtained on the multiple choice questionnaire. She gave them a sheet of paper on which they could write down their name if they were interested in receiving these pieces of information and, in this case, to check the box corresponding to the information they wanted. Students could then request none of these pieces of information, one of them, or both. Out of the 63 participants, 14 $(22.2 \%)$ requested only the more detailed text, 14 (22.2\%) requested only

Table 5

Study 2: Goal Endorsement and Reported Competence

\begin{tabular}{|c|c|c|c|c|c|}
\hline Variable & $M$ & $S D$ & Observed range & $\begin{array}{c}\text { Possible } \\
\text { range }\end{array}$ & $\alpha$ \\
\hline Mastery goals & 5.35 & 1.18 & $2.67-7.00$ & $1-7$ & .67 \\
\hline Performance goals & 3.33 & 1.54 & $1.00-6.67$ & $1-7$ & .87 \\
\hline Perceived self-competence & 4.53 & 0.92 & $2.00-6.33$ & $1-7$ & .68 \\
\hline Perceived other's competence & 4.42 & 1.50 & $1.00-7.00$ & $1-7$ & .95 \\
\hline
\end{tabular}


the grade, and $24(38.1 \%)$ requested both. Eleven (17.5\%) did not request either piece of information.

\section{Results}

\section{Factorial Structure of the Scales}

As in Study 1, in preliminary analyses, factor analyses were conducted on the six goals items via principal-components extraction with promax rotation. The analysis revealed the expected two-factor structure of the scale: Factor 1 accounted for $43.8 \%$ of the variance and comprised the three performance goals items. Factor 2 accounted for $29.2 \%$ of the variance and consisted of the three mastery goals items. All items loaded above .65 on their primary factor. Scale reliabilities are presented in Table 5.

\section{Achievement Goals as Predictors of Perceived Self- and Other's Competence}

Zero-order correlations are reported in Table 6. As in Study 1, we conducted regression analyses with three predictors: performance goals, mastery goals, and their interaction. In preliminary analyses, gender (coded -1 for men, 1 for women) and age were included in the analyses. Neither gender $(B=0.04 ; t<1)$ nor age $(B=0.05 ; t<1)$ predicted self-competence $(B=0.05, t<1$, for age; $B=0.04, t<1$, for gender). Neither did they predict the other's competence: $B=-0.25, t<1$, for age; $B=0.27, t(53)=$ $1.2, p=.24$, for gender. Finally, they did not significantly predict either the request for the grade $\left(B=-0.18\right.$, Wald $\chi^{2}<1$, for age; $B=-0.33$, Wald $\chi^{2}<1$, for gender) or the request for the text, $B=-0.82$, Wald $\chi^{2}(1, N=63)=3.35, p<.07$, for age; $B=$ -0.16 , Wald $\chi^{2}<1$, for gender. Complete analyses of covariance (Yzerbyt et al., 2004) were conducted with gender and age. Because the inclusion of these variables did not change the effects, they were removed from the final model.

Reported other's competence. As expected, mastery goals significantly predicted reports of the other's competence $(B=0.38)$, $t(55)=2.26, p<.03\left(\eta^{2}=.06\right)$. The more participants endorsed mastery goals, the more they thought their partner was competent. Neither performance goals $(B=-0.05 ; t<1)$ nor the interaction $(B=0.17), t(55)=1.61, p=.11\left(\eta^{2}=.02\right)$, significantly predicted perception of the other's competence.

Reported self-competence. We thought that performance goals should enhance reported self-competence, given that the enhancement of one's own competence is an indication of relational conflict regulation. This is what we observed. As expected, performance goals significantly predicted the reported amount of self-competence $(B=0.22), t(57)=2.87, p<.003\left(\eta^{2}=.13\right)$. The more participants endorsed performance goals, the more they

Table 6

Study 2: Zero-Order Correlations Among Variables

\begin{tabular}{llccl}
\hline \multicolumn{1}{c}{ Variable } & 1 & 2 & 3 & 4 \\
\hline 1. Mastery goals & $-\overline{12}$ & & & \\
2. Performance goals & $.24 \dagger$ & -.03 & - & \\
3. Reported other's competence & .09 & $.35^{* *}$ & .04 & - \\
4. Reported self-competence & .09 & & &
\end{tabular}

reported being competent. Neither mastery goals $(B=0.01 ; t<1)$ nor the interaction between the two variables $(B=-0.03 ; t<1)$ significantly predicted reported self-competence.

\section{Achievement Goals as Predictors of Interest in Different Kinds of Information}

For each of the two pieces of information, participants were coded as 1 if they requested it and 0 if they did not. As a consequence, interest in a more detailed text and in the grade were both nominal variables, so logistic regression was used to analyze these data.

Detailed text. We expected mastery goals to favor the request for the more detailed text, and results confirmed this prediction: Mastery goals significantly predicted the request for the text $(B=$ $0.55)$, Wald $\chi^{2}(1, N=63)=4.88, p<.03$. The more participants endorsed mastery goals, the more they asked for the detailed text. Neither performance goals $(B=0.02)$, Wald $\chi^{2}(1, N=63)=.02$, $p=.88$, nor the interaction between the two variables $(B=0.11)$, Wald $\chi^{2}(1, N=63)=0.48, p=.45$, significantly predicted the request for the text.

Grade. We expected performance goals to predict the request for the grade obtained on the bogus multiple choice questionnaire. As expected, the more participants endorsed performance goals, the more they asked for their grade $(B=0.41)$, Wald $\chi^{2}(1, N=$ $63)=4.22, p<.04$. Neither mastery goals $(B=-0.21)$, Wald $\chi^{2}(1, N=63)=0.73, p=.39$, nor the interaction between the two variables $(B=0.22)$, Wald $\chi^{2}(1, N=63)=1.75, p=.19$, significantly predicted the request for the multiple choice questionnaire grade. A summary of regression parameters is presented in Table 4.

\section{Discussion}

Study 1 showed that mastery and performance goals predicted different self-reported modes of conflict regulation. Study 2 completes Study 1's results by finding similar results on a different and more subtle measure of conflict regulation and in a real sociocognitive conflict situation. In particular, the results indicate that achievement goals predicted different ways to attribute competence inside the dyad. Mastery goals enhanced recognition of the partner's competence, whereas performance goals enhanced the assertion of one's own competence. ${ }^{2}$ As mentioned earlier, the competence attributed to oneself and to the source of the sociocognitive conflict is an indication of the mode of conflict regulation (Butera \& Mugny, 1995). However, this measure is more subtle than direct self-report items in that instead of asking participants to report what they did during the interaction, it consists of asking them to make a judgment about themselves and about the other person. In spite of this difference in the nature of the dependent variables, the present results provide convergent evidence to those obtained with the direct self-report items used in Study 1.

\footnotetext{
${ }^{2}$ Let us note that the means for competence attributed to oneself and to the source of the conflict (see Table 5) allow for the interpretation that participants were uncertain about their own level of competence as well as the source's level, as both means were close to the midpoint of the scale.
} 
These results confirm our hypotheses and show that reporting perceived self- and other's competence after a sociocognitive conflict can have a motivational function. Many authors have argued that people always try to maintain a positive self-evaluation (e.g., Steele, 1988; Tesser, 1988). As we have already mentioned, in a sociocognitive conflict situation, self-competence may be threatened. One way to cope with this threat is to enhance reported self-competence and thus restore a positive image of the self. This process is interesting because it only resulted from the endorsement of performance goals; mastery goals did not lead to the same reaction. Consistent with what other research has shown, mastery goals did not render students concerned with the question of competence evaluation (Jagacinski \& Nicholls, 1987; Sansone, 1986) and willing to perceive the other as a threat to their competence. Instead, mastery goals favored a representation of other persons as informational supports, as a means to improve knowledge (Newman, 1990; A. M. Ryan \& Pintrich, 1997). As a consequence, these goals made participants more likely to react to sociocognitive conflict by recognizing and enhancing reports of the other's competence rather than their own.

Results of this study also indicate that goals affected the information students were interested in after the sociocognitive conflict. In this interpersonal situation, as was the case in individual situations (e.g., Butler, 1992, 1993), mastery goals favored interest in the instructive information, the text, whereas performance goals favored the search for the normative evaluative information, the grade.

\section{General Discussion}

As mentioned earlier, the situation of sociocognitive conflict is particular in the sense that it introduces a doubt about one's knowledge and competence (Butera \& Mugny, 2001; McGarty, Turner, Oakes, \& Haslam, 1993). In both studies, participants were confronted with clear, credible disagreement. With respect to Study 1 , the personality interpretation of compliance with authority is commonly observed in introductory classes and corresponds to what Hewson and Hewson (1984) or Posner, Strike, Hewson, and Gertzog (1982) would refer to as the naive model or misconceptions - that is, the naive conception students have before being taught the scientific model. As far as the second study is concerned, all the disagreements were based on possible misunderstanding of the text. Eylon and Linn (1988) would refer to these answers as coherent incorrect models, Hewson and Hewson (1984) as plausible conceptions. In other words, these answers were credible from the participants' point of view.

The present studies specify two modes of regulation for coping with sociocognitive conflict: epistemic regulation, which is focused on task understanding and examination of the validity of each proposition, and relational regulation, which corresponds to a defense of one's own competence through affirmation of one's own point of view (Mugny et al., 2003). These two studies support the idea that mastery goal endorsement predicts epistemic regulation, whereas performance goal endorsement predicts relational regulation.

It is worth mentioning that the two studies differed in their population (college students vs. high school students). Because age has been shown to be a possible moderator of goals effects (Anderman, Austin, \& Johnson, 2002) and because it seems reasonable to think that conflict regulation skills may increase with age (Sandy \& Cochran, 2000), one could expect differences between these two populations. However, the links between goals and conflict regulation were observed in both of these age groups. These two studies also differed in terms of the dependent variables used to assess conflict regulation. Once again, it is interesting to note that, despite these differences, the same dynamics were observed in the two studies. That is, mastery goals predicted epistemic conflict regulation, whereas performance goals predicted relational conflict regulation. This was the case on the direct self-report items of conflict regulation (Study 1) as well as on a more subtle measure of conflict regulation (Study 2), which together converge to pinpoint the links between achievement goals and conflict regulation.

We have already discussed the fact that most of the studies carried out in the achievement goals field have examined the way individuals cope with the task, but at an intraindividual level. Rare are the studies examining the effects of achievement goals on social variables, such as perception of others and the ways to interact with them (for exceptions, see Gabriele \& Montecinos, 2001; Kaplan, 2004). The classroom, however, is a place in which students are not alone and in which they have to contend not only with the academic material but also with other students. The results of these two studies represent in this sense a significant contribution to this literature. First, research has shown that mastery and performance goals lead to interest in different kinds of information, but these effects have only been examined in individual settings. Study 2 extends these findings to a social situation. Second, these studies address the question of achievement goal effect on social outcomes, given that both Study 1 and Study 2 show that achievement goals strongly affected the way participants judged others and responded to them in a sociocognitive conflict situation.

Moreover, in the sociocognitive conflict literature, epistemic and relational regulations are very often invoked to explain the effects of sociocognitive conflict in different situations (e.g., competition, competence threat). However, regulation strategies had never been examined directly, the dependent measures being influence (e.g., Mugny, Tafani, Butera, \& Pigière, 1999), strategies of reasoning (e.g., Butera \& Mugny, 1995), or cognitive progresses (e.g., Doise \& Mugny, 1984). The two studies we present fill in this gap by showing that the two modes of conflict regulation can be assessed by both direct self-report measures and more subtle measures, such as attribution of competence. In the same vein, it is worth noting that in this literature, motivation is often invoked to explain why situational variables, such as competitive context or asymmetry of competences, can influence the effects of sociocognitive conflict. However, the different modes of conflict regulation had never previously been linked directly to personal motivational variables. The contribution of the two studies presented, then, is also to show this link explicitly by suggesting that mastery and performance goals are motivational variables that influence the mode of conflict regulation.

In spite of the contribution these two studies represent for the literature on achievement goals as well as the literature on conflict regulation, some limitations may be noted. First, the fact that these studies are both correlational makes it impossible to establish a causal link between goals and conflict regulation. Moreover, it is worth noting that this research was carried out on a sample that 
was mainly composed of women. Many researchers have documented a gender effect both on conflict resolution strategies (e.g., Holt \& DeVore, 2005; Reinisch \& Sanders, 1986) and on goal endorsement (e.g., Dweck, 1986). As a consequence, it seems reasonable to think that male participants might not have reacted to the sociocognitive conflict in the same way. In particular, because they have been shown to be less likely to use cooperation strategies in conflict situation than women, one could perhaps expect male participants to regulate sociocognitive conflict in a relational way regardless of the level of goal endorsement. Future research is necessary to test this idea in a sample that is evenly composed of male and female participants.

Finally, recent research has shown that relational conflict regulation can actually take two different forms: If defending and asserting one's own competence is one way to address threat, complying and adopting the other's point of view is another way to do so (Darnon, Butera, Mugny, \& Quiamzade, 2006). Similarly, as mentioned in the introduction, performance goals can be either performance-approach or performance-avoidance goals (Elliot, 1997; Elliot \& Harackiewicz, 1996). The only performance goals examined in this study were performance-approach goals. Would performance-avoidance goals lead to the same conflict regulation? We do not think so. In particular, we think that performanceavoidance goals, because they are linked to a weak competence expectancy, might favor compliance. Future research is needed to examine this point.

Those limitations notwithstanding, this article is the first empirical evidence that endorsed mastery and performance goals affect conflict regulation. As mentioned earlier, this point contributes to both research on conflict regulation and research on achievement goals. In addition, this article underlines the beneficial consequence of mastery goals rather than performance goals when participants are led to discuss conflicting viewpoints. Indeed, the conflict regulation literature has consistently argued that sociocognitive conflict leads to more positive outcomes when it is regulated in an epistemic way than when it is regulated in a relational way (Butera \& Mugny, 1995; Darnon, Buchs, \& Butera, 2002; Doise \& Mugny, 1984). These two studies show that one way to orient students to epistemic conflict regulation is to enhance mastery goals.

\section{References}

Ames, C., \& Archer, J. (1988). Achievement goals in the classroom: Students' learning strategies and motivation processes. Journal of Educational Psychology, 80, 260-267.

Ames, C., Russel, A., \& Felker, D. W. (1977). Effects of competitive reward structure and valence of outcome on children's achievement attributions. Journal of Educational Psychology, 69, 1-8.

Anderman, E. M., Austin, C. C., \& Johnson, D. M. (2002). The development of goal orientation. In A. Wigfield \& J. Eccles (Eds.), Developmental perspectives on achievement motivation (pp. 197-220). San Diego, CA: Academic Press.

Barron, K., \& Harackiewicz, J. M. (2000). Achievement goals and optimal motivation: A multiple goals approach. In C. Sansone \& J. M. Harackiewicz (Eds.), Intrinsic and extrinsic motivation: The search for optimal motivation and performance (pp. 229-254). San Diego, CA: Academic Press.

Barron, K., \& Harackiewicz, J. M. (2001). Achievement goals and optimal motivation: Testing multiple goal models. Journal of Personality and Social Psychology, 80, 706-722.
Beauregard, K. S., \& Dunning, D. (1998). Turning up the contrast: Selfenhancement motives prompt egocentric contrast effects in social judgments. Journal of Personality and Social Psychology, 74, 606-621.

Berlyne, D. E. (1960). Conflict, arousal, and curiosity. New York: McGraw-Hill.

Buchs, C., Butera, F., Mugny, G., \& Darnon, C. (2004). Conflict elaboration and cognitive outcomes. Theory Into Practice, 43, 23-30.

Butera, F., Gardair, E., Maggi, J., \& Mugny, G. (1998). Les paradoxes de l'expertise: Influence sociale et (in)compétence de soi et d'autrui [Paradox of expertise: Social influence and (in)competence of self and other]. In J. Py, A. Somat, \& J. Baillé (Eds.), Psychologie sociale et formation professionnelle: Propositions et regards critiques (pp. 111123). Rennes, France: Presses Universitaires de Rennes.

Butera, F., Huguet, P., Mugny, G., \& Pérez, J. A. (1994). Socio-epistemic conflict and constructivism. Swiss Journal of Psychology, 53, 229-239.

Butera, F., \& Mugny, G. (1995). Conflict between incompetences and influence of a low expertise source in hypothesis testing. European Journal of Social Psychology, 25, 457-462.

Butera, F., \& Mugny, G. (2001). Conflicts and social influences in hypothesis testing. In C. K. W. De Dreu \& N. K. De Vries (Eds.), Group consensus and minority influence: Implications for innovation (pp. 161182). Cambridge, MA: Blackwell.

Butera, F., Mugny, G., \& Tomei, A. (2000). Incertitude et enjeux identitaires dans l'influence sociale [Uncertainty and identity stakes in social influence]. In J.-L. Beauvois, R.-V. Joule, \& J.-M. Monteil (Eds.), Perspectives cognitives et conduites sociale (Vol. 7, pp. 205-229). Rennes, France: Presses Universitaires de Rennes.

Butler, R. (1992). What young people want to know when: Effects of mastery and ability goals on interest in different kinds of social comparisons. Journal of Personality and Social Psychology, 62, 934-943.

Butler, R. (1993). Effects of task- and ego-achievement goals on information seeking during task engagement. Journal of Personality and Social Psychology, 65, 18-31.

Butler, R., \& Neuman, O. (1995). Effects of task and ego achievement goals on help-seeking behaviors and attitudes. Journal of Educational Psychology, 87, 261-271.

Cheung, P. C., Ma, H. D., \& Shek, D. T. L. (1998). Conceptions of success: Their correlates with prosocial orientation and behaviour in Chinese adolescents. Journal of Adolescence, 21, 31-42.

Covington, M. V. (1984). The motive for self-worth. In C. Ames \& R. Ames (Eds.), Research on motivation in education (Vol. 1, pp. 77-113). New York: Academic Press.

Covington, M. V. (1992). Making the grade. A self-worth perspective on motivation and school reform. Cambridge, England: Cambridge University Press.

Cury, F., Sarrazin, P., \& Famose, J. P. (1997). Achievement goals, perceived ability and active search for information. European Yearbook of Sport Psychology, 1, 166-183.

Darnon, C., Buchs, C., \& Butera, F. (2002). Epistemic and relational conflict in sharing information during cooperative learning. Swiss Journal of Psychology, 61, 139-151.

Darnon, C., \& Butera, F. (2005). Buts d'accomplissement, stratégies d'étude, et motivation intrinsèque: Présentation d'un domaine de recherche et validation française de l'échelle d'Elliot et McGregor (2001). [Achievement goals, study strategies, and intrinsic motivation: Presentation of a line of research and French validation of Elliot and McGregor's (2001) scale]. Année Psychologique, 105, 105-131.

Darnon, C., Butera, F., Mugny, G., \& Quiamzade, A. (2006). Performanceapproach and avoidance goals in social interaction: Toward the distinction between two modes of relational conflict regulation. Unpublished manuscript.

Deutsch, M. (1973). The resolution of conflict: Constructive and destructive processes. New Haven, CT: Yale University Press.

Diener, C. I., \& Dweck, C. S. (1980). An analysis of learned helplessness: 
II. The processing of success. Journal of Personality and Social Psychology, 39, 940-952.

Doise, W., \& Mugny, G. (1984). The social development of the intellect. Oxford, England: Pergamon Press.

Drozda-Senkowska, E., \& Personnaz, B. (1988). Rôle du contexte normatif sur l'effet de Pollyanne: 1. Compétition et diminution du penchant positif dans les jugements d'autrui [Role of normative context on the Pollyanna effect: 1 . Competition and reduction of the positive bias in judging others]. Revue Internationale de Psychologie Sociale, 1, 41-50.

Dunning, D., Leuenberger, A., \& Sherman, D. A. (1995). A new look at motivated inference: Are self-serving theories of success a product of motivational forces? Journal of Personality and Social Psychology, 69, $58-68$.

Dweck, C. S. (1986). Motivational processes affecting learning. American Psychologist, 41, 1040-1048.

Dweck, C. S. (1992). The study of goals in psychology. Psychological Science, 3, 165-167.

Dweck, C. S., \& Leggett, E. L. (1988). A social-cognitive approach to motivation and personality. Psychological Review, 95, 256-273.

Elliot, A. J. (1997). Integrating the "classic" and "contemporary" approaches to achievement motivation: A hierarchical model of approach and avoidance motivation. In M. Maehr \& P. Pintrich (Eds.), Advances in motivation and achievement (Vol. 10, pp. 143-179). Greenwich, CT: JAI Press.

Elliot, A. J., \& Harackiewicz, J. M. (1996). Approach and avoidance achievement goals and intrinsic motivation: A mediational analysis. Journal of Personality and Social Psychology, 70, 461-475.

Elliot, A. J., \& McGregor, H. A. (2001). A $2 \times 2$ achievement goal framework. Journal of Personality and Social Psychology, 80, 501-519.

Elliot, A. J., McGregor, H. A., \& Gable, S. (1999). Achievement goals, study strategies, and exam performance: A mediational analysis. Journal of Educational Psychology, 91, 549-563.

Eylon, B. S., \& Linn, M. C. (1988). Learning and instruction: An examination of four research perspectives in science education. Review of Educational Research, 58, 251-301.

Gabriele, A. J., \& Montecinos, C. (2001). Collaborating with a skilled peer: The influence of achievement goals and perception of partners' competence on the participation and learning of low-achieving students. Journal of Experimental Education, 69, 152-176.

Harackiewicz, J. M., Barron, K. E., Carter, S. M., Lehto, A. T., \& Elliot, A. J. (1997). Predictors and consequences of achievement goals in the college classroom: Maintaining interest and making the grade. Journal of Personality and Social Psychology, 73, 1284-1295.

Harackiewicz, J. M., Barron, K., \& Elliot, A. J. (1998). Rethinking achievement goals: When are they adaptive for college students and why? Educational Psychologist, 33, 1-21.

Harackiewicz, J. M., Barron, K. E., Pintrich, P. R., Elliot, A. J., \& Thrash, T. M. (2002). Revision of achievement goal theory: Necessary and illuminating. Journal of Educational Psychology, 94, 638-645.

Harackiewicz, J. M., Barron, K. E., Tauer, J. M., Carter, S. M., \& Elliot, A. J. (2000). Short-term and long-term consequences of achievement goals: Predicting interest and performance over time. Journal of Educational Psychology, 92, 316-330.

Harackiewicz, J. M., Barron, K. E., Tauer, J. M., \& Elliot, A. J. (2002). Predicting success in college: A longitudinal study of achievement goals and ability measures as predictors of interest and performance from freshman year through graduation. Journal of Educational Psychology, 94, 562-575.

Hewson, P. T., \& Hewson, M. G. (1984). The role of conceptual conflict in conceptual change and the design of science instruction. Instructional Science, 13, 1-13.

Heyman, G. D., \& Dweck, C. S. (1992). Achievement goals and intrinsic motivation: Their relation and their role in adaptive motivation. Motivation and Emotion, 16, 231-247.
Holt, J. L., \& DeVore, C. J. (2005). Culture, gender, organizational role, and styles of conflict resolution: A meta-analysis. International Journal of Intercultural Relations, 29, 165-196.

Jagacinski, C. M., \& Nicholls, J. G. (1987). Competence and affect in task involvement and ego-involvement: The impact of social comparison information. Journal of Educational Psychology, 79, 107-114.

Johnson, D. W., \& Johnson, R. T. (1985). Classroom conflict: Controversy versus debate in learning groups. American Educational Research Journal, 22, 237-256.

Johnson, D. W., Johnson, R. T., \& Smith, K. (2000). Constructive controversy: The educative power of intellectual conflict. Change, 32, 29-37.

Kaplan, A. (2004). Achievement goals and intergroup relations. In P. R. Pintrich \& M. L. Maehr (Eds.), Advances in research on motivation and achievement: Vol. 13. Motivating students, improving schools: The legacy of Carol Midgley (pp. 97-136). Amsterdam: Elsevier.

Karabenick, S. A. (2003). Seeking help in large college classes: A personcentered approach. Contemporary Educational Psychology, 28, 37-58.

Koestner, R., Zuckerman, M., \& Koestner, J. (1987). Praise, involvement, and intrinsic motivation. Journal of Personality and Social Psychology, 53, 383-390.

Levy, I., Kaplan, A., \& Patrick, H. (2004). Early adolescents' achievement goals, social status, and attitudes towards cooperation with peers. Social Psychology of Education, 43(2), 1-33.

Limon, M. (2001). On the cognitive conflict as an instructional strategy for conceptual change: A critical appraisal. Learning and Instruction, 11, $357-380$

MacCallum, R. C., Widaman, K. F., Zhang, S., \& Hong, S. (1999). Sample size in factor analysis. Psychological Methods, 4, 84-99.

Maehr, M. L. (1984). Meaning and motivation: Toward a theory of personal investment. In C. Ames \& R. Ames (Eds.), Research on motivation in education (Vol. 1, pp. 115-144). New York: Academic Press.

McGarty, C., Turner, J. C., Oakes, P. J., \& Haslam, S. A. (1993). The creation of uncertainty in the influence process: The roles of stimulus information and disagreement with similar others. European Journal of Social Psychology, 23, 17-38.

Middleton, M., \& Midgley, C. (1997). Avoiding the demonstration of lack of ability: An underexplored aspect of goal theory. Journal of Educational Psychology, 89, 710-718.

Midgley, C., Kaplan, A., \& Middleton, M. (2001). Performance-approach goals: Good for what, for whom, under what circumstances, and at what cost? Journal of Educational Psychology, 93, 77-86.

Milgram, S. (1974). Obedience to authority. New York: Harper \& Row.

Mugny, G., Butera, F., Quiamzade, A., Dragulescu, A., \& Tomei, A. (2003). Comparaisons sociales des compétences et dynamiques d'influence sociale dans les tâches d'aptitudes [Social comparison of competences and social influence dynamics in aptitude tasks]. L'Année Psychologique, 104, 469-496.

Mugny, G., De Paolis, P., \& Carugati, F. (1984). Social regulations in cognitive development. In W. Doise \& A. Palmonari (Eds.), Social interaction in individual development (pp. 127-146). Cambridge, England: Cambridge University Press.

Mugny, G., Lévy, M., \& Doise, W. (1978). Conflit socio-cognitif et développement cognitif [Socio-cognitive conflict and cognitive development]. Revue Suisse de Psychologie, 37, 22-43.

Mugny, G., Tafani, E., Butera, F., \& Pigière, D. (1999). Contrainte et dépendance informationnelles: Influence sociale sur la représentation du groupe d'amis idéal [Informational constraint and dependence: Social influence on the representation of the ideal group of friends]. Connexions, 72, 55-72

Newman, R. S. (1990). Children's help-seeking in the classroom: The role of motivational factors and attitudes. Journal of Educational Psychology, $82,71-80$

Nicholls, J. G. (1984). Achievement motivation: Conceptions of ability, 
subjective experience, task choice, and performance. Psychological Review, 91, 328-346.

Nolen, S. B. (1988). Reasons for studying: Motivational orientations and study strategies. Cognition and Instruction, 5, 269-287.

Ohlsson, S. (1996). Learning from performance errors. Psychological Review, 103, 241-262.

Piaget, J. (1985). The equilibration of cognitive structures. Chicago: University of Chicago Press.

Pintrich, P., \& Schunk, D. (2002). Motivation in education: Theory, research, and applications (2nd ed.). Upper Saddle River, NJ: Merrill Prentice-Hall.

Posner, G. J., Strike, K. A., Hewson, P. W., \& Gertzog, W. A. (1982). Accommodation of a scientific conception: Towards a theory of conceptual change. Science Education, 66, 211-227.

Quiamzade, A., \& Mugny, G. (2001). Social influence dynamics in aptitude tasks. Social Psychology of Education, 4, 311-334.

Quiamzade, A., Tomei, A., \& Butera, F. (2000). Informational dependence and informational constraint: Social comparison and social influences in an anagram resolution task. International Review of Social Psychology, $15,123-150$.

Rawsthorne, L., \& Elliot, A. J. (1999). Achievement goals and intrinsic motivation: A meta-analytic review. Personality and Social Psychology Review, 3, 326-344.

Reinisch, J. M., \& Sanders, S. A. (1986). A test of sex differences in aggressive response to hypothetical conflict situations. Journal of Personality and Social Psychology, 50, 1045-1049.

Ryan, A. M., \& Pintrich, P. R. (1997). Should I ask for help? The role of motivation and attitudes in adolescents' help seeking in math class. Journal of Educational Psychology, 89, 329-341.

Ryan, A. M., Pintrich, P. R., \& Midgley, C. (2001). Avoiding seeking help in the classroom: Who and why? Educational Psychology Review, 13, 93-114.

Ryan, R. M. (1982). Control and information in the intrapersonal sphere:
An extension of cognitive evaluation theory. Journal of Personality and Social Psychology, 43, 450-461.

Sandy, S. V., \& Cochran, K. M. (2000). The development of conflict resolution skills in children: Preschool to adolescence. In M. Deutsch \& P. T. Coleman (Eds.), The handbook of conflict resolution: Theory and practice (pp. 316-342). San Francisco: Jossey-Bass.

Sansone, C. (1986). A question of competence: The effects of competence and task feedback on intrinsic interest. Journal of Personality and Social Psychology, 51, 918-931.

Sapnas, K. G., \& Zeller, R. A. (2002). Minimizing sample size when using exploratory factor analysis for measurement. Journal of Nursing Measurement, 10, 135-154.

Sears, D. O. (1983). The person-positivity bias. Journal of Personality and Social Psychology, 44, 233-250.

Steele, C. M. (1988). The psychology of self-affirmation: Sustaining the integrity of the self. In L. Berkowitz (Ed.), Advances in experimental social psychology (Vol. 21, pp. 261-302). San Diego, CA: Academic Press.

Tesser, A. (1988). Toward a self-evaluation maintenance model of social behavior. In L. Berkowitz (Eds.), Advances in experimental social psychology (Vol. 21, pp. 181-227). San Diego, CA: Academic Press.

Tjosvold, D., Johnson, D. W., \& Fabrey, L. J. (1980). Effect of controversy and defensiveness on cognitive perspective taking. Psychological Reports, 47, 1043-1053.

Urdan, T. C. (1997). Achievement goal theory: Past results, future directions. In M. Maehr \& P. Pintrich (Eds.), Advances in motivation and achievement (Vol. 10, pp. 99-141). Greenwich, CT: JAI Press.

Yzerbyt, V., Muller, D., \& Judd, C. M. (2004). Adjusting researchers' approach to adjustment: On the use of covariates when testing interactions. Journal of Experimental Social Psychology, 40, 424-431.

Received October 24, 2005

Revision received July 18, 2006

Accepted July 18, 2006 